\title{
The Emerging Role of Ion Channels in the Pathophysiology and Treatments of Asthma
}

\author{
Jingwen $\mathrm{Zhu}^{1 *}$ \\ ${ }^{1}$ St. Michaels University School, Victoria, British Columbia, Canada
}

\begin{abstract}
Asthma is one of the most common chronic respiratory diseases in the world. Although treatments and medications that can control the symptoms of asthma are available, no cure has been developed. Ion channels are transmembrane proteins that facilitate the diffusion of ions across membranes. In the airways, ion channels are involved in signalling between cells and regulation of intracellular ion concentration, which may lead to the activation of airway cells, immune cells, and neurons. This review mainly focuses on discoveries made so far in animal models and clinical trials regarding ion channels and asthma and gives some insight into developing treatments targeting ion channels.
\end{abstract}

\section{Introduction}

Asthma is prevalent around the world. It is the most common chronic disease among children. According to the World Health Organization, more than 339 million people are living with asthma, and over $80 \%$ of asthmarelated deaths occur in low-and lower-middle-income countries [1]. It was estimated that more than 339 million people worldwide had asthma in 2016 [2]. According to the 2020 Global Strategy for Asthma Management and Prevention, asthma is a heterogeneous disease, usually characterized by chronic airway inflammation and remodeling [3]. Airway remodeling includes airway contraction, airway thickening, and mucus overproduction, which may be caused by airway hyperresponsiveness (AHR). Airway inflammation is shown by increased levels of immune cells such as T cells, cytokines, mast cells, and immunoglobulin E (IgE) [4]. During an asthma attack, the smooth muscles around the airway tighten, and extra mucus is produced and blocks the airways. As a result, the airways become narrower, causing difficulty in breathing. The inflammatory response that leads to AHR and remodeling is originally thought to be T helper 2 (Th2)-driven, but it is now considered highly heterogeneous [5]. The early asthmatic response (EAR) takes place when the immune system recognizes the inhaled allergens. With the energy provided by increased glycolysis and mitochondrial activity, increased concentration of $\mathrm{Ca}^{2+}$ helps promote the EAR, and by binding with calmodulin, it also induces airway smooth muscle (ASM) contraction [6]. EAR is usually followed by the late asthmatic response (LAR), which may be initiated by allergens that trigger the nervous system [7]. Asthma has been studied for centuries, and no efficient treatment has yet been found. Therefore, there is a need of developing new effective treatments for this disease.
Ion channels are transmembrane proteins with pores that allow ions to pass through cell membranes down their concentration gradients. They regulate many cell functions that are involved in the pathophysiology of asthma. The activation and deactivation of ion channels induce changes in intracellular ion concentrations which may lead to physiological changes present in patients with asthma. Therefore, ion channels, including voltage-gated calcium channels (VGCCs), $\mathrm{K}^{+}$channels, transient receptor potential (TRP) channels, $\mathrm{Cl}^{-}$channels, and $\mathrm{Na}^{+}$ channels, have been widely studied for drug discovery purposes. Primary studies focusing on developing VGCC blockers as bronchodilators were not effective [8]. Then the focus moved on to $\mathrm{K}^{+}$channels that adjust membrane potential and activate VGCCs. More recent studies center around TRP channels on neurons, which greatly contribute to cough reflexes.

This review summarizes the most broadly studied ion channels that are associated with asthma and their clinical manifestations that are investigated in animal models and clinical trials.

\section{Asthma and Calcium Channels}

\subsection{Voltage-gated $\mathrm{Ca}^{2+}$ channels}

Typical VGCCs are composed of five subunits: $\alpha_{1}, \alpha_{2} \delta, \beta$, and $\gamma$, organized in four repeating domains ( I -IV) [9]. The $\alpha_{1}$ subunit contains four homologous domains. Each domain is composed of six transmembrane helices (S1-S6) with S1-S4 forming the voltage-sensing domains, and tetramerized S5 and S6 forming the pore [9]. The $\alpha_{2} \delta$ dimer is $\alpha_{2}$ and $\delta$ linked together by a disulfide bond. Coexpression of the $\alpha_{2} \delta$ subunit and especially the $\beta$ subunit enhances the level of expression and confers more normal gating properties of VGCCs [9]. The $\beta$ subunit is

\footnotetext{
*Corresponding author: zjw2004judy@126.com
} 
intracellular and without transmembrane segments. It binds to the $\alpha$ interaction domain (AID) in the $\alpha_{1}$ subunit located in the first half of the intracellular loop connecting the domains I and II [9]. The AID forms an $\alpha$ helix bound tightly to a groove in the guanylate kinase domain of the $\beta$ subunit [9]. The $\gamma$ subunit, whose function is unknown yet, is a glycoprotein with four transmembrane segments [9].

VGCCs initiate ASM remodeling directly by transporting $\mathrm{Ca}^{2+}$ across the cell membrane. When VGCCs are in resting states, intracellular $\mathrm{Ca}^{2+}$ concentrations in ASM cells remain low. When VGCCs are activated, $\mathrm{Ca}^{2+}$ influx and thus ASM contraction takes place [10]. Removal of $\mathrm{Ca}^{2+}$ completely blocks collagen matrix contraction mediated by sphingolipid sphingosine1-phosphate (S1P), which can induce human airway smooth muscle (HASM) contraction [11]. Three of the most highly expressed VGCCs in human airway epithelium are $\mathrm{Ca}_{\mathrm{v}} 1, \mathrm{Ca}_{\mathrm{v}} 2$, and $\mathrm{Ca}_{\mathrm{v}} 3$ channels [12]. Among them, $\mathrm{Ca}_{\mathrm{v}} 1$ channels are most widely studied. Verapamil, a $\mathrm{Ca}_{\mathrm{v}} 1$ channel blocker, can decrease S1Pinduced HASM cell contraction greatly [11]. Furthermore, deficiency in $\mathrm{Ca}_{\mathrm{v}} 1$ channels is associated with airway remodeling and AHR that increase with age [13]. $\mathrm{Ca}_{\mathrm{v}} 1$ channel knockdown increases the thickness of the subepithelial matrix, which may lead to an increase in AHR in 6- or 12-month-old mice compared to wild-type mice [13]. $\mathrm{Ca}_{\mathrm{v}} 1$ channel deficiency also causes a steady increase in the thickening of the subepithelial matrix in 12-month-old mice compared to 1-or 3-month-old mice [13]. In addition, two opposing $\mathrm{Ca}^{2+}$ signaling pathways are discovered, through which bitter tastants activate bitter taste receptors (TAS2Rs). These two pathways are the activation of the canonical TAS2R signaling and the inhibition of $\mathrm{Ca}_{\mathrm{v}} 1$ [14]. The TAS2R signaling pathway leads to a temperate rise in $\mathrm{Ca}^{2+}$ concentrations and does not affect contraction, while the inhibition of $\mathrm{Ca}_{\mathrm{v}} 1$ by biter tastants reverses the increase in $\mathrm{Ca}^{2+}$ concentration induced by bronchoconstrictors, methacholine and $\mathrm{KCl}$ and results in the relaxation of ASM cells [14]. Moreover, inhibition of VGCCs by gallopamil in the airways is able to reduce BSM thickness but does not affect the epithelial area, the subepithelial membrane thickness, or the lamina propria thickness [15]. In one study, the mean percentage of variation in the normalized BSM thickness decreased by $13.7 \%$ within the gallopamil group, whereas it remained nearly stable within the placebo group [15]. The mean wall thickness of bronchi, assessed from the second to the fourth generation, was significantly decreased at Month 12 compared with that at Month 0 in the gallopamil group, whereas the wall thickness remained unchanged in the placebo group [15]. During the follow-up studies, there was also a significant decrease in asthma exacerbations. However, further studies with larger groups of patients will be required to approve this result [15].

VGCCs control Ca2+ signals in immune cells and induce immune responses. T helper 2 (Th2) cells but not $\mathrm{T}$ helper 1 (Th1) cells transfected with Cav1 antisense oligodeoxynucleotides can damage $\mathrm{Ca} 2+$ signaling, decrease IL-4 concentration in the bronchoalveolar lavage fluid and the number of lymphocytes in the lymph nodes and thus lose their ability to induce airway inflammation [16]. Inhibiting Cav1 channels may selectively impair Th2-cell activation but not affecting other $T$ cells that can induce an immune response against infectious agents [16]. Through the Th2 cell paradigm, allergens induce airway contraction in two phases. The 'early phase' is a fall in forced expiratory volume in 1 minute (FEV1) that begins within several minutes, peaks by 30 minutes, and improves over several hours [17]. The 'late phase' is the second fall in FEV1 hours later [17]. As summarized in a review by Barrett, Nora A Austen, and K Frank, some features of asthma cannot be explained by the Th2 cell paradigm alone. These features include neutrophilic inflammation without eosinophils, the presence of airways inflammation - eosinophil influx and degranulated mast cells - in non-allergic asthma, limited therapeutic efficacy, and the success of interventions directed against IL- 4 and IL-13 by administration of antibodies that prevent the binding of $\operatorname{IgE}$ to high-affinity IgE receptor or neutralize IL-5, viral infections as a common trigger for exacerbation in both atopic and nonatopic asthma, and late phase of AHR being susceptible to inhibitors that are not capable of improving the 'intrinsic' or inflammation-independent AHR [17]. More complex immune responses that involve allergens such as dust mites or molds include the participation of Th1, Th2, Th17, natural killer T cells, and airway epithelial cells [17]. Besides Ca v1 channels, Cav3.1 are also expressed on $\mathrm{T}$ cells. However, they do not play a role in $\mathrm{T}$ cell development [18]. On the contrary, they mediate $\mathrm{Ca} 2+$ influx and regulate the production of inflammatory factors such as cytokines and granulocyte-macrophage colonystimulating factor (GM-CSF) [18].

\subsection{Store-operated $\mathrm{Ca}^{2+}$ channels}

Store-operated $\mathrm{Ca}^{2+}$ channels (SOCC) are a group of $\mathrm{Ca}^{2+}$ channels expressed on the endoplasmic reticulum (ER) [19]. They are not voltage-gated but are activated by stromal interaction molecule (STIM) proteins and Orai proteins and respond to the sarcoplasmic reticulum (SR) or ER depletion of $\mathrm{Ca}^{2+}$ triggered by inositol trisphosphate $\left(\mathrm{IP}_{3}\right)$ [19]. STIM proteins function as ER $\mathrm{Ca}^{2+}$ sensors for store-operated $\mathrm{Ca}^{2+}$ entry (SOCE), and Orai proteins function as SOCC subunits [19].

SOCCs are a major route for $\mathrm{Ca}^{2+}$ influx in cells that induces $\mathrm{Ca}^{2+}$ oscillations. Sustained $\mathrm{Ca}^{2+}$ oscillations main contribute to airway contraction. Early models showed that the $\mathrm{Ca}^{2+}$ influx pathway is deterministic in ASM cells: initially transient and then sustained [10, 20]. More recent models showed that $\mathrm{Ca}^{2+}$ oscillations are inherently stochastic [21,22]. Moreover, $\mathrm{Ca}^{2+}$ oscillations are more likely to be sustained by $\mathrm{Ca}^{2+}$ entry through SOCE because a small amount of agonist-induced $\mathrm{Ca}^{2+}$ oscillations are caused or sustained by VGCCs [10]. The transient $\mathrm{Ca}^{2+}$ oscillations depend on $\mathrm{Ca}^{2+}$ release from the internal stores and do not require extracellular $\mathrm{Ca}^{2+}$ influx, while the sustained $\mathrm{Ca}^{2+}$ oscillations, and thus ASM contraction, depends on $\mathrm{Ca}^{2+}$ influx from SOCE and requires $\mathrm{Ca}^{2+}$ influx to compensate for the $\mathrm{Ca}^{2+}$ depletion 
[10]. The frequency of $\mathrm{Ca}^{2+}$ oscillations regulates the extent of ASM contraction and is determined by the activation of $\mathrm{IP}_{3}$ receptors ( $\mathrm{IP}_{3} \mathrm{Rs}$ ) on the membrane of the ER/SR by $\mathrm{IP}_{3}$ produced by phospholipase $\mathrm{C}$ [21]. The length of the period is determined by diffusive coupling between and within $\mathrm{IP}_{3} \mathrm{R}$ clusters rather than the change in the rate of $\mathrm{Ca}^{2+}$ inhibition by $\mathrm{IP}_{3} \mathrm{R}$ [21]. When $\mathrm{IP}_{3} \mathrm{Rs}$ are activated, SOCCs open and allow a rapid flow of $\mathrm{Ca}^{2+}$ out of the ER/SR and thus a rise in cytosolic $\mathrm{Ca}^{2+}$ concentration, which directly induces ASM contraction.

Inhibition of SOCCs reduces the secretion of inflammatory mediators in the airways. In rats, YM58483, a blocker of SOCE that mediates the activation of non-excitable cells, inhibits both lieutenant production and histamine release induced by DNP-albumin bovine (BSA) in a concentration-dependent manner [23]. In human peripheral blood cells, phytohemagglutinin-P, an activator of SOCE in T cells, significantly stimulates the production of IL- 5 and IL-13, which can be inhibited by YM-58483 in a concentration-dependent manner [23]. In guinea pigs, the inhibition of SOCC suppresses ovalbumin (OVA)-induced bronchoconstriction and AHR by reducing the releasing of inflammatory mediators that are probably produced through $\mathrm{T}$ cells [23].

SOCCs may also induce ASM cell proliferation by allowing $\mathrm{Ca}^{2+}$ influx through SOCE. During ASM cell proliferation in rats, SOCE is upregulated and accompanied by a mild increase of STIM1 and a significant increase of Orail mRNA expression [24]. Inhibition of SOCC or removal of STIM and Orail proteins can reduce ASM cell proliferation, which is a feature of asthma [24]. In addition, the ASM cell proliferation is partially inhibited by SOCC blockers, SKF-96365, $\mathrm{NiCl}_{2}$, and BTP-2, and the knockdown of STIM1 or Orail with specific short hairpin RNA results in the attenuation of SOCE and ASM cell proliferation [24]. Moreover, SOCCs may be a route for $\mathrm{Ca}^{2+}$ entry into mitochondria and induce BSM cell proliferation. According to clinical research, there is an increase in mitochondrial mass and oxygen consumption in asthmatic patients due to an increase in extracellular $\mathrm{Ca}^{2+}$ influx upon activation of asthmatic BSM cells [25]. In the presence of glucose, which allows both aerobic and anaerobic glycolysis to take place, Asthmatic BSM cell growth significantly increased compared with that of COPD and control subjects [25]. The mitochondria biogenesis and thus BSM proliferation was inhibited when a $\mathrm{Ca}^{2+}$ influx was blocked by methoxyverapamil, a $\mathrm{Ca}^{2+}$ channel blocker [25]. The mechanism behind these phenomena may be that mitochondria rapidly take up $\mathrm{Ca}^{2+}$ that has been released and increases mitochondrial metabolism, enabling stores to empty for SOCCs to be activated [26]. $\mathrm{IP}_{3}$ Rs are suggested to combine with the voltage-dependent anion channel of the outer mitochondrial membrane to form a route for $\mathrm{Ca}^{2+}$ transport across the mitochondrial membranes and regulate $\mathrm{Ca}^{2+}$ accumulations in the mitochondria [27]. Lose connections result in slow propagation of $\mathrm{Ca}^{2+}$ to the mitochondria, while tightened connections tend to result in high propagation of $\mathrm{Ca}^{2+}$ to the mitochondria and thus the overloading of $\mathrm{Ca}^{2+}$ in mitochondria [28].

\section{Asthma and Potassium Channels}

\subsection{Voltage-gated $\mathrm{K}^{+}$channels}

Voltage-gated $\mathrm{K}^{+}\left(\mathrm{K}_{\mathrm{v}}\right)$ channels share a similar tetrameric structural scaffold with those of VGCCs, with four voltage-sensing domains surrounding a central pore domain. Like VGCCs, the first four helices (S1-S4) form the voltage-sensing domain and the last two helices (S5S6) form the pore domain responsible for transporting $\mathrm{K}^{+}$ ions [29]. A variety of family members of $K_{v}$ channels such as $K_{v} 1$ and $K_{v} 7$ have been studied. In addition, a subfamily that can be activated by $\mathrm{Ca}^{2+}$ is $\mathrm{Ca}^{2+}$-activated $\mathrm{K}^{+}$channel $\left(\mathrm{K}_{\mathrm{Ca}}\right)$ channel, including large-conductance $\mathrm{Ca}^{2+}$-activated $\mathrm{K}^{+}$channel $\left(\mathrm{BK}_{\mathrm{Ca}}\right)$, intermediate conductance $\mathrm{Ca}^{2+}$-activated $\mathrm{K}^{+}$channel $\left(\mathrm{IK}_{\mathrm{Ca}}\right)$, and small conductance $\mathrm{Ca}^{2+}$-activated $\mathrm{K}^{+}$channel $\left(\mathrm{SK}_{\mathrm{Ca}}\right)$. Their currents can be amplified by the binding of $\mathrm{Ca}^{2+}$. Only $\mathrm{IK}_{\mathrm{Ca}}$ and $\mathrm{SK}_{\mathrm{Ca}}$ channels have a protein called calmodulin on the $\mathrm{C}$-terminal which allows $\mathrm{Ca}^{2+}$ to bind and amplify the current.

Firstly, $K_{v}$ channels may contribute to airway remodeling by regulating $\mathrm{K}^{+}$currents and membrane potential in ASM cells. Studies of $\mathrm{K}_{\mathrm{v}} 7$ activators suggest that $\mathrm{K}_{\mathrm{v}} 7$ mainly involve in airway contraction. In guineapig, rat, and human ASM cells, $\mathrm{G}_{\mathrm{q} / 11}$-coupled bronchoconstrictor agonists methacholine and histamine significantly suppress $\mathrm{K}_{\mathrm{v}} 7$ currents which are restored by flupirtine, a $\mathrm{K}_{\mathrm{v}} 7$ activator restores the current amplitudes $[30,31]$. In human lung slices, XE991, a $\mathrm{K}_{\mathrm{v}} 7$ blocker, induces a near-total contraction of small airways and similar quantity in larger airways, but the bronchoconstrictor's effect can be fully reversed by the addition of verapamil, a $\mathrm{Ca}^{2+}$ channel blocker [30]. The combination of formoterol, a bronchodilator, with retigabine, a $\mathrm{K}_{\mathrm{v}} 7$ activator, prevented methacholineinduced airway constriction and enhanced the relaxation of the rat airways [31]. In addition to $\mathrm{K}_{\mathrm{v}} 7$ channels, the opening of $\mathrm{BK}_{\mathrm{Ca}}$ channels has also been found to involve in the relaxation of the airways. Through a pathway that involves the activation of $\mathrm{K}_{\mathrm{v}}$ and $\mathrm{BK}_{\mathrm{Ca}}$ channels, lippia origanoides essential oils (LOO), indicated to treat asthma, relax guinea-pig isolated trachea pre-contracted with $\mathrm{KCl}$, histamine or carbachol [32]. This mechanism may involve the stimulation of soluble guanylyl cyclase (sGC) which increases the activity of cGMP-dependent protein kinase (PKG) and thus the phosphorylation of $\mathrm{K}_{\mathrm{v}}$ and $\mathrm{K}_{\mathrm{Ca}}$ channels [32]. Furthermore, in the presence of $\mathrm{K}^{+}$channel blockers 4-aminopyridine or tetraethylammonium, a larger amount of LOO is required to relax the guinea-pig trachea compared to the situation when they are absent [32]. Moreover, the activity of $\mathrm{BK}_{\mathrm{Ca}}$ channels can prevent the enhancement of airway contraction in allergic asthma [33]. In mice models, stimulation of $\mathrm{BK}_{\mathrm{Ca}}$ channels by estrogen reduces carbachol-induced contractility, while $\mathrm{BK}_{\mathrm{Ca}}$ channel inhibitors suppress the outward currents and attenuate the effects [33]. Some $\mathrm{IK}_{\mathrm{Ca}}$ channels are also involved in airway contraction and mucus secretion. For example, gene deletion of $\mathrm{K}_{\mathrm{Ca}} 3.1$ decreases the isometric contractile force that is increased by methacholine in the 
bronchi of OVA-sensitized mice models of chronic asthma [34].

Secondly, $K_{v}$ channels may regulate mucociliary dysfunction and thus mucus production, which may be a major cause of airway obstruction. For instance, the inactivation of $\mathrm{BK}_{\mathrm{Ca}}$ channels may cause a decrease in the rate of mucus clearance (MCC). Overexpression of the pore-forming subunit of $\mathrm{BK}_{\mathrm{Ca}}, \mathrm{KCNMA1}$, increases $\mathrm{BK}_{\mathrm{Ca}}$ activity in normal human airway epithelial cells and prevents airway surface liquid (ASL) volume depletion induced by IFN- $y$ which decreases CBF and ASL volume in normal human airway epithelial cells [35]. The rate of MCC and thus the amount of ASL is determined by the ciliary beat frequency $(\mathrm{CBF})$ : the lesser $\mathrm{CBF}$, the greater possibility that the airways will be filled with mucus and trigger a lung infection. The addition of ASL without a change in the amount of IFN- $y$ raises CBF back to normal, so the change of $\mathrm{CBF}$ was due to ASL volume depletion but not the direct impact of IFN-y [35]. In the IK $\mathrm{Ca}$ family, $\mathrm{K}_{\mathrm{Ca}} 3.1$ channel may play a role in mucus overproduction. Gene deletion of $\mathrm{K}_{\mathrm{C} a} 3.1$ significantly decreases the number of mucus-secreting goblet cells in OVAsensitized mice models of chronic asthma compared to the wild-type mice group [34]. While OVA-sensitized mice models show up-regulation of $\alpha$-SMA protein staining, mice models after knockout of $\mathrm{K}_{\mathrm{Ca}} 3.1$ exhibit significantly less $\alpha$-SMA protein staining in the bronchi and thus a smaller ASM mass.

In addition, $\mathrm{K}_{\mathrm{v}}$ channels may be involved in cell proliferation in asthma. $\mathrm{K}_{\mathrm{Ca}} 3.1$ inhibition by basic fibroblast growth factor (bFGF) reduces HASM cell proliferation while $\mathrm{K}_{\mathrm{Ca}} 3.1$ activity and $\mathrm{HASM}$ cell proliferation increase significantly due to the addition of transforming growth factor beta (TGf- $\beta$ ) before bFGF stimulation [36]. In contrast, inhibition of $\mathrm{K}_{\mathrm{Ca}} 1.1$ by iberiotoxin does not prevent bFGF-induced HASM cell proliferation [36]. In human $\mathrm{BSM}$ cells, $\mathrm{K}_{\mathrm{Ca}} 3.1$ and TRPV4 channels are colocalized [34]. The expressions of $\mathrm{K}_{\mathrm{Ca}} 3.1$ and TRPV4 channels are 2-fold and 1.5-fold higher than wild-type mice [34]. Activation of $\mathrm{K}_{\mathrm{Ca}} 3.1$ by 1-EBIO hyperpolarizes the membrane potential of human BSM cells and enhances $\mathrm{Ca}^{2+}$ influx, while siTRPV4 attenuates the $\mathrm{Ca}^{2+}$ influx induced by 1-EBIO [34]. Thus, $\mathrm{K}_{\mathrm{Ca}} 3.1$ may induce membrane hyperpolarization and lead to $\mathrm{Ca}^{2+}$ influx through TRPV4. The proliferation of human BSM cells may be dependent on the $\mathrm{Ca}^{2+}$ influx through TRPV4. It is significantly attenuated in the cells transfected with either siTRPV4 or siKCa3.1, suggesting that both of these channels may play a part in BSM cell proliferation [34].

Furthermore, $\mathrm{K}_{\mathrm{v}}$ channels regulate the activity of immune cells, especially $\mathrm{T}$ cells, and the following immune response. For example, $\mathrm{K}_{\mathrm{v}} 1.3$ channels may contribute to the activity of $T$ cells, and $\mathrm{K}_{\mathrm{v}} 1.5$ channels may decrease the effect of $\mathrm{K}_{\mathrm{v}} 1.3$ inhibition. $\mathrm{K}_{\mathrm{v}} 1.3$ and $\mathrm{K}_{\mathrm{v}} 1.5$ channels are highly expressed in $\mathrm{T}$ cells and macrophages in asthma patients [37]. They form a complex within a cell, but the ratio of their expression is different in various cells. $\mathrm{K}_{\mathrm{v}} 1.3$ channels are expressed on IFN $\gamma$-producing $\mathrm{T}$ cells. Inhibition of $\mathrm{K}_{\mathrm{v}} 1.3$ channels can activate resting T cells and thus the production of IL-4 [38, 39] but not the mitogenesis of preactivated T cells [39].
Currents in bone marrow-derived macrophages are mainly generated by $\mathrm{K}_{\mathrm{v}} 1.3$ channels, and the expression of $\mathrm{K}_{\mathrm{v}} 1.5$ channels can decrease the currents [37]. Therefore, the efficiency of blocking $\mathrm{K}_{\mathrm{v}} 1.3$ channels might be questioned. $\mathrm{IK}_{\mathrm{Ca}}$ channels may also contribute to immune responses. The blocking of $\mathrm{IK}_{\mathrm{Ca}}$ channel by nitrendipine, clotrimazole, and charybdotoxin decreases $T$ cell proliferation, and clotrimazole is more potent than nitrendipine and charybdotoxin [40]. Therefore, as an $\mathrm{IK}_{\mathrm{Ca}}$ and CRAC channel blocker, clotrimazole may work together with cyclosporin $\mathrm{A}$ and inhibit $\mathrm{T}$ cell proliferation inhibiting CRAC channels as well as $\mathrm{IK}_{\mathrm{Ca}}$ channels [40]. In general, maximal inhibition of $\mathrm{IK}_{\mathrm{Ca}}$ channels accounts for a $40 \%-50 \%$ inhibition of the $\mathrm{T}$ cell proliferation [40]. In addition to clotrimazole's effect on attenuating $\mathrm{T}$ cell proliferation, the inhibition of $\mathrm{IK}_{\mathrm{Ca}}$ channel by clotrimazole also reduces the release of IFN- $y$ from activated T cells [40]. Knockdown of $\mathrm{K}_{\mathrm{ca}} 3.1$ channel, an $\mathrm{IK}_{\mathrm{Ca}}$ channel, decreases IgE-dependent release of histamine in marrow-derived mas cells [41]. $\mathrm{Ca}^{2+}$ entry upon endothelin-1 stimulation is significantly reduced in $\mathrm{K}_{\mathrm{ca}} 3.1$ knockdown cells, and Ag-induced mast cell degranulation, indicated by the release of $\beta$ hexosaminidase, is significantly smaller in $\mathrm{K}_{\mathrm{ca}} 3.1$ knockdown mast cells [41]. Knockout of $\mathrm{K}_{\mathrm{Ca}} 3.1$ also attenuates the up-regulation of IL-4, IL-5, and IL- 13 and increased concentrations of IFN- $\gamma$, compared with OVAsensitized mice models on chronic asthma [34].

\subsection{Inwardly rectifying $\mathrm{K}^{+}$channels}

Similar to a typical $\mathrm{K}_{\mathrm{v}}$ channel, inwardly rectifying $\mathrm{K}^{+}$ channel $\left(\mathrm{K}_{\mathrm{ir}}\right)$ is also tetramerized with a pore between two transmembrane helices and amino and carboxyl termini located on the cytoplasmic side of the membrane [42]. Considering their differences, a $\mathrm{K}_{\mathrm{ir}}$ channel is structurally more simplified with only two transmembrane helices and no voltage-sensing domains [42]. In addition to its extracellular and extracellular gates in the transmembrane domain, there is also a flexible third gate called G-loop, which is located at the apex of the cytosolic domain and forms a girdle around the central fourfold axis [29]. In addition, $\mathrm{K}_{\mathrm{ir}}$ channels conduct $\mathrm{K}^{+}$ions on hyperpolarization, rather than depolarization as in other $\mathrm{K}^{+}$channels because they are blocked by intracellular $\mathrm{Mg}^{+}$ ions and polyamines on depolarization but conduct $\mathrm{K}^{+}$ ions into the cell on hyperpolarization when the blockers are released [29]. $\mathrm{K}_{\mathrm{ATP}}$ channels, which belong to the $\mathrm{K}_{\mathrm{ir}}$ family are composed of $\mathrm{K}_{\mathrm{ir}} 6$ subunits that form the pore and sulfonylurea receptors (SURs) that are sensitive to adenosine triphosphate (ATP). These channels are inhibited by ATP molecules and conduct inward rectifying currents. Studies suggest that they may be involved in AHR, airway remodeling, and ASM cell proliferation. For example, 2-(3,4-dihydro-2,2-dimethyl6-nitro-2H-1,4-benzoxazin-4-yl) pyridine N-oxide, a $\mathrm{K}_{\text {ATP }}$ channel opener, inhibits airway hyperresponsiveness induced by platelet-activating factor in guinea-pig models and human ASM cells [43]. Another example is that $\mathrm{H}_{2} \mathrm{~S}$, identified as an opener of $\mathrm{K}_{\text {ATP }}$ channels [44], reduces OVA-induced airway 
inflammation and airway remodeling in rat models [45] and causes relaxation of HASM cells [46]. Furthermore, pinacidil, a $\mathrm{K}_{\mathrm{ATP}}$ channel opener, can relax HASM cells, and the relaxation can be completely inhibited by the treatment with a $\mathrm{K}_{\mathrm{ATP}}$ channel blocker glibenclamide [46]. Mitochondrial $\mathrm{K}_{\mathrm{ATP}}$ channels play an important role in balancing the $\mathrm{K}^{+}$concentration in mitochondria. The application of diazoxide, an opener of mitochondrial $\mathrm{K}_{\mathrm{ATP}}$ channels, significantly enhances the levels of reactive oxygen species (ROS), HASM cell proliferation, and TGf- $\beta_{1}$ mRNA expression in asthmatic models [47].

\subsection{Tandem pore domain $\mathrm{K}^{+}$channels}

Compared to other $\mathrm{K}^{+}$channels, tandem pore domain $\mathrm{K}^{+}$ channel $\left(\mathrm{K}_{2 \mathrm{P}}\right)$ channels have several distinct features. Mammalian $\mathrm{K}_{2 \mathrm{P}}$ channel is a dimer with four transmembrane domains and two pore-forming domains, similar to a tandem of two $\mathrm{K}_{\mathrm{ir}}$ channel subunits. Unlike other $\mathrm{K}^{+}$channels, which are highly regulated, $\mathrm{K}_{2 \mathrm{P}}$ channels are usually constitutively open [29]. Human $K_{2 P}$ channels have a unique rhomboid-shaped helical cap that is located on top of the transmembrane part and formed by the extracellular region within the first pore-forming domain but is absent in the second pore-forming domain [29]. The few studies done regarding $\mathrm{K}_{2 \mathrm{P}}$ channels and their relationship with asthma suggest that $\mathrm{K}_{2 \mathrm{P}}$ channels may be associated with immune responses in the airways. $\mathrm{K}_{2 \mathrm{P}} 6.1$ channels in macrophages have a fundamental role in activating the nucleotide-binding oligomerization domain-like receptor containing pyrin domain 3 (NLRP3) inflammasome and thus inflammation [48]. $\mathrm{K}_{2 \mathrm{P}} 6.1$ may activate NLRP3 inflammasome via activating P2X7 receptor, an ATP-gated non-selective cation channel that mediates $\mathrm{K}^{+}$efflux [48]. Their cooperation enables $\mathrm{Ca}^{2+}$ and $\mathrm{Na}^{+}$influx to change the membrane potential and the latter enables $\mathrm{K}^{+}$efflux to activate NLRP3 inflammasome [48]. Furthermore, inhibition of $\mathrm{K}_{2 \mathrm{P}} 6.1$ suppresses the activation of NLRP3 inflammasome in mouse bonemarrow-derived macrophages and the release of cytokine IL-1 $\beta$, IL-18, and TNF $\alpha$ [48].

\section{Asthma and TRP Channels}

Similar to voltage-gated ion channels, a typical transient receptor potential (TRP) channel is a tetramer with each subunit containing six transmembrane helices with a poreforming loop between the fifth (S5) and the sixth (S6) [49]. Compared with a voltage-gated ion channel, it has similar domains to the voltage-sensing domain. However, it does not have a positively charged arginine residue that functions as a voltage sensor. In addition, it has more aromatic residues that can overlap with each other, making it generally more tightly packed than a voltagegated ion channel. A TRP channel's carboxyl and amino termini are intracellular with different lengths depending on which subfamily it belongs to. The most widely studied TRP channel families include transient receptor potential vanilloid (TRPV), transient receptor potential canonical (TRPC), transient receptor potential melastatin (TRPM), and transient receptor potential ankyrin (TRPA) channels. TRPV contains 3-6 N-terminals ankyrin repeats; TRPC contains 3-4 N-terminal ankyrin repeats; TRPM lacks the ankyrin repeats but has considerably longer N-terminals than other TRP subfamilies; TRPA1 channels are the only type of TRPA protein present in mammals and contain 14 $\mathrm{N}$-terminal ankyrin repeats. Regarding the C-terminal, both TRPC and TRPM channels contain a 25 amino acid motif known as the TRP motif containing a TRP box [49]. The gating mechanism varies greatly among the TRP family, and many TPR channels can be activated by multiple different stimuli such as voltage, heat, chemicals, $\mathrm{pH}$, temperature, and mechanical stress [49]. All TRP channels are cation permeable, but the permeability of different ions varies among different subfamilies. For example, Relative permeability to $\mathrm{Ca}^{2+}$ compared to $\mathrm{Na}^{+}$ ranges from $>100$ for TRPV5 and TRPV6 to $\sim 0$ for TRPM4 and TRPM5 [49].

\subsection{Transient receptor potential vanilloid channels}

TRPV channels regulate neurons in the airways and are suggested to be the main contributor to cough reflexes. In guinea-pig models of asthma, inhibition of TRPV1 channels by V112220 decreases $73 \%$ of coughs evoked by citric acid, which activates A- $\delta$ fibres and vagal $C$-fibre nerves partly via the activation of TRPV1 channels [50], and $70 \%$ coughs induced by capsaicin compared to the control groups [51]. In a clinical trial performed in 250 patients with chronic refractory cough and 56 healthy subjects, $98.3 \%$ patients and $96.2 \%$ healthy subjects reached two coughs $(\mathrm{C} 2)$, and $96.6 \%$ of patients and $90.6 \%$ healthy subjects reached C5 during the application of capsaicin (Figure 1) [52]. Besides, the sensitivity of capsaicin was significantly higher in patients than in healthy subjects and higher in males than in females [52]. 


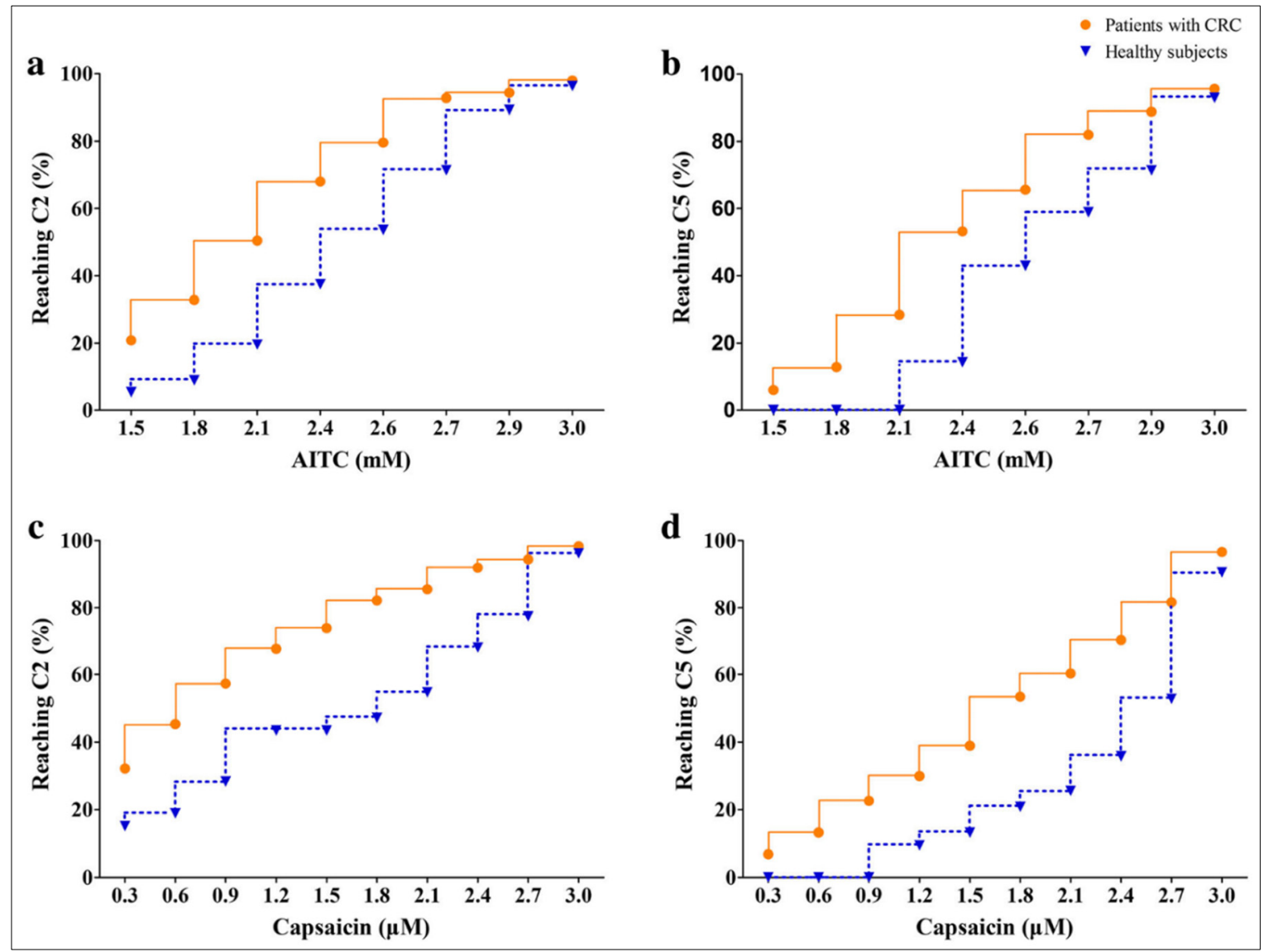

Fig 1. Concentration-dependent induction of coughs to reach either C2 or C5. AITC cough challenge (Panels a and b), capsaicin cough challenge (Panels c and d). C2: the lowest concentrations of AITC or capsaicin which evoked two to four coughs; C5: the lowest concentrations of AITC or capsaicin which evoked five coughs or more. The solid lines with dots represent patients with chronic refractory cough $(\mathrm{CRC})$ and the dashed lines with triangles represent healthy subjects Comparison.

TRPV channels, specifically TRPV1 channels, are involved in allergen-induced airway inflammation and remodeling. When co-exposed to PM2.5 and formaldehyde, TRPV1 channels are sensitive to the air pollutants and enhance allergic asthma with increased levels of ROS, inflammatory factors, and total serum IgE [53]. The increase in TRPV1 channel expression induces elevated capsaicin sensitivity and airway inflammation in rats. In OVA-sensitized rats, the same dose of capsaicin induces more pronounced pulmonary chemoreflex responses, which are normally not activated by capsaicin, and a significant increase in the proportion of TRPV1expressing pulmonary neurons in nodose ganglia [54]. Additionally, TRPV1 inhibition reduces airway epithelial injury in mice and attenuates infiltration of inflammatory cells and airway structural changes such as goblet cell and subepithelial fibrosis that are induced by IL-13 [55]. Other TRPV channels such as TRPV4 channels may be dispensable for the development of allergic asthma [56]. TRPV4 knockout and wild-type mice sensitized and challenged by OVA express similar levels of allergenspecific IgE, Th2 cytokines, and eosinophils [56]. Although TRPV4 knockout mice have slightly higher AHR in response to increasing doses of $\beta$-methacholine than wild-type mice, there are no significant differences in airway resistance between these groups [56].

\subsection{Transient receptor potential melastatin channels}

Like TRPV channels, TRPM channels may also contribute to airway inflammation and remodeling. In asthmatic patients, TRPM8 protein levels are significantly higher than that of normal controls [57]. TRPM8 channels are especially known for the sensitivity of cold temperatures. Activation of TRPM8 channels by cold $\left(18^{\circ} \mathrm{C}\right)$ treatments increases the mRNA expression of cytokine and chemokine genes, including IL-1 $\alpha,-1 \beta,-4,-$ $6,-8$, and -13, GM-CSF, and TNF- $\alpha$ [58]. Similarly, activation of TRPM8 channels by menthol can lead to a significant increase in the mRNA expression of IL-25, IL33 , and thymic stromal lymphopoietin in bronchial epithelial cells [57]. This increase can be abolished by a TRPM8 antagonist, BCTC [57]. Activation of TRPM8 may inhibit ASM cell contraction [59]. The application of TRPM8 inhibitors, icilin and menthol, attenuates airway contraction and $\mathrm{Ca}^{2+}$ influx induced by $\mathrm{MCh}$ and high $\mathrm{K}^{+}$. In addition, inhibition of $\mathrm{MCh}$-induced contraction by menthol is significantly greater at room temperature than at $37^{\circ} \mathrm{C}$, also suggesting the involvement of TRPM8 [59]. Another group of TRPM channels is TRPM4 channels, which are important regulators for mast cells. Knockdown of TRPM4 channels in mice leads to a $\mathrm{Ca}^{2+}$ influx in mast 
cells, increased release of histamine, leukotrienes and TNF, and a more severe acute anaphylactic response [60]. However, TRMP4's anticipation in allergic asthma remains to be further proved.

Other TRPM channels such as TRPM2 channels may have but less effect on asthma comparing to TRPM8 and TRPM4. OVA-sensitized wild-type and TRPM2 knockout mice have similar airway resistance and severity of mucus-producing goblet cell hyperplasia [61]. After repeated OVA treatment, there is no apparent difference between IgE and cytokine levels of wild-type, and TRPM2 knockout mice [61]. However, this study is done in severe asthma models and TRPM2 channels appear to be involved in certain inflammatory responses that are mediated by chemokine production in response to ROS, so investigations with less severe asthma models may be needed [61].

\subsection{Transient receptor potential ankyrin channels}

TRPA1 channels play an important part in asthmatic responses and cough reflexes via regulating neurons in the airways. Expression of TRPA1 channels stimulates vagal pulmonary C-fibre and shows a dose-dependent marked prolongation of the time of braking with a similar magnitude to that of capsaicin evoked response in respiration, while TRPM8 channels may not play a role in this mechanism [62]. Activation of TRPA1 channels by allergens may initiate a central reflex that leads to a parasympathetic, cholinergic constrictor response and induces the LAR [7]. A TRPA1 selective inhibitor, HC030031, can inhibit OVA-induced LAR in both rat and murine asthma models, while TRPV1 channel inhibitors, JNJ-17203212 and capsazepine, cannot reduce the allergen-induced airway responses in the models [7]. In addition, activation of neurons via the opening of TRPA1 channels may also contribute to cough. In the clinical trial regarding cough and TRPV1 channels that was mentioned previously, $98.0 \%$ of patients and $96.4 \%$ of healthy subjects reached $\mathrm{C} 2$, and $95.6 \%$ of patients and $92.9 \%$ of healthy subjects reached C5 during the application of allyl isothiocyanate (AITC), a selective TRPA1 agonist (Figure 1) [52]. In addition, Among the 234 patients who finished both the AITC and capsaicin challenges, 25 (10.7\%) had hypersensitivity to both AITC and capsaicin, $44(18.8 \%)$ showed hypersensitivity solely to AITC, 28 (11.9\%) demonstrated hypersensitivity solely to capsaicin, and $137(58.6 \%)$ had no evidence of heightened sensitivity to either capsaicin or AITC (Table 1) [52]. Furthermore, the sensitivity of AITC was significantly higher in patients than in healthy subjects and higher in males than in females, like that of capsaicin [52]. However, since AITC had to be dissolved in ethanol, ethanol may be a factor that magnified cough [52]. Combining with what was mentioned above regarding TRPV1, activation of TRPV1 and TRPA1 channels expressed in vagal pulmonary $\mathrm{C}$-fibre sensory nerves together or individually may contribute to cough [52].
Table1. TRPA1-, TRPV1-mediated cough hypersensitivity in patients with chronic refractory cough.

\begin{tabular}{lllll}
\hline & & \multicolumn{2}{l}{ Capsaicin } & Total \\
\cline { 2 - 4 } & & + & - & \\
\hline AITC & + & $25(10.7)$ & $44(18.8)$ & $69(29.5)$ \\
& - & $28(11.9)$ & $137(58.6)$ & $165(70.5)$ \\
Total & & $53(22.6)$ & $181(77.4)$ & $234(100)$ \\
\hline
\end{tabular}

Data are expressed as $\mathrm{n}(\%)$. +: Increased cough sensitivity to AITC or capsaicin; -: Normal cough sensitivity to AITC or capsaicin

TRPA1 channels contribute to inflammatory responses in the airways especially under huge temperature changes or when co-expressed with other TRP channels. In OVA-challenged mice, temperature fluctuation, especially repeated exposure to the variations, significantly increases TRPA1 expression as well as inflammation [63]. The inhibition of TRPA1 by HC030031 significantly reduces the increase of $\operatorname{IgE}, \operatorname{IgG} 1$, IL-4, IL-6, IL-13 and GM-CSF levels in the OVAinduced groups of mice [63]. The activation of TRPA1 channels induces the production of ROS due to mitochondrial dysfunction. The peripheral terminals of sensory nerves have a great number of mitochondria. Acute mitochondrial dysfunction caused by antimycin A is likely to produce ROS, which can rapidly activate TRPA1 and airway sensory nerves and induce cough, dyspnea, bronchospasm, and hypersecretion [64, 65]. Reversely, removal of ROS is able to significantly inhibit the antimycin A-induced increase in TRPA1 open probability [64]. Application of TRPA1 and TRPV1 inhibitors, HC-030031 and I-RTX, both decrease antimycin A-induced $\mathrm{Ca}^{2+}$ influx in dissociated vagal neurons, although I-RTX is less effective [64]. An allergen of the airways, diesel exhaust particle (DEP), is shown to activate aryl hydrocarbon receptor and subsequent mitochondrial ROS production [66]. TRPA1 channels on nociceptive $\mathrm{C}$-fibres may respond to the produced ROS and induce respiratory reflexes [66]. Janssen 130, a TRPA1 channel antagonist significantly inhibits DEP-organic extract-induced depolarization in isolated guinea pig vagus nerve, while Xention D0501, a TRPV1 antagonist and GSK2193874, and a TRPV4 antagonist, had no effect [66]. When co-expressed with TRPV1, activation of TRPA1 in dorsal root ganglia neurons increases TRPV1 activity via $\mathrm{Ca}^{2+}$ influx and the production of cAMP/protein kinase A (PKA), and the removal of extracellular $\mathrm{Ca}^{2+}$ and the inhibition of PKA prevent TRPV1 sensitization afterward [67]. Since both TRPA1 and TRPV1 contribute to pain sensitization, the cross-sensitization of these channels may contribute to enhanced pain sensitivity in inflamed tissues [67].

\subsection{Transient receptor potential canonical channels}

TRPC channels may play a role in ASM remodeling and airway cell proliferation. The expression of TRPC1, TRPC3 and TRPC6 but not TRPC4, TRPC5 and TRPC7 are upregulated in asthmatic mouse ASM cells [68]. Among the TRPC channels that are upregulated in 
asthmatic mice, TRPC1 and TRPC3 induce ASM cell proliferation by increasing $\mathrm{Ca}^{2+}$ concentration in murine asthma models when overexpressed [68]. In addition, the application of SKF96365, a TRPC channel blocker, and TRPC1 or TRPC 3 knockdown completely conversed the effects [68]. In ASM cells transfected with siTRPC1 or siTRPC 3, the expression of factors associated with the growth of ASM cells, including p-p38, p-c-Jun aminoterminal kinase, and cleaved caspase- 3 significantly increases and anti-apoptotic Bcl-2 significantly decreases [68].

TRPC6 channels may contribute to airway inflammation and hyperresponsiveness in allergic asthma. In TRPC6 deficient mice, TRPC mRNA level is elevated 3-4 folds, and MCh-induced AHR and agonist-induced contractility of tracheal rings are increased. Knockdown of TRPC6 channels also reduces the levels of airway eosinophils, blood IgE, and bronchoalveolar lavage Th2 cytokines (IL-5, IL-13) [69]. However, TRPC6 deficiency does not affect lung mucus production after allergen challenge [69].

\subsection{Other transient receptor potential channels}

Other TRP channels include transient receptor potential polycystin channels, transient receptor potential canonical channels, transient receptor potential mucolipin channels, and transient receptor potential no mechanoreceptor potential C channels. They are not as well understood as the ones mentioned previously, so further studies may be needed to discover their relationships with asthma.

\section{Asthma and $\mathrm{Cl}^{-}$Channels}

As a recently discovered family of ion channels, $\mathrm{Cl}^{-}$ channels are extremely diverse and poorly understood. They are permeable to many different ions but are named $\mathrm{Cl}^{-}$channel because $\mathrm{Cl}^{-}$is the most abundant anion in organisms and hence is the predominant permeating species under most circumstances [70]. Families of $\mathrm{Cl}^{-}$ channels that are most possibly involved in the development of asthma include $\mathrm{Cl}^{-}$channel accessory (CLCA), a putative $\mathrm{Ca}^{2+}$ activated $\mathrm{Cl}^{-}$channel $(\mathrm{CaCC})$, and cystic fibrosis transmembrane conductance regulator (CFTR) [70]. CFTR has two blocks containing six putative transmembrane spanning domains each and separated by a cytoplasmic region that contains the first nucleotide-binding fold and the regulatory R domain [70]. However, it is not yet firmly established whether CFTR functions as a monomer or as a dimer [70].

\section{$5.1 \mathrm{Cl}^{-}$channel accessory}

In the CLCA family, CLCA1 mainly contributes to mucus overproduction via different mechanisms. Firstly, CLCA1 activates the expression of mucins like MUC5AC and leads to IL9 and IL13-driven mucus overproduction in human airways [71, 72]. IL-9 is essential in inflammatory responses and airway hyperresponsiveness in asthma [73]. Regarding IL9-driven mucus overproduction, the mechanism involves CLCA1 is unknown, while for IL13- driven mucus overproduction, CLCA1 may activate MAPK13 which in turn stimulates MUC5AC [72]. Another mechanism involves the activation of TMEM16A, a CaCC present in HASM cell. CLCA1 activity is induced by $\mathrm{Ca}^{2+}$ and leads to upregulation of TMEM16A that strongly contribute to mucus secretion and thus increases $\mathrm{Ca}^{2+}$ dependent $\mathrm{Cl}^{-}$currents [74]. In addition, this induction can be reduced by tannic acid, an inhibitor of TMEM16A [74]. The activation of TMEM16A may lead to $\mathrm{Cl}_{2}$-induced membrane depolarization and initiate a series of proinflammatory events that lead to oxidative stress [75].

CLCAs may also contribute to airway inflammation by regulating immune cells. CLCA3 is identified in the lung epithelium of IL-9 transgenic and antigen-exposed asthmatic mice [76]. The expression of CLCA3 can be induced by intratracheal administration of IL-9 or other Th2 cytokines (IL-4, IL-13), but not by interferon- $\gamma$ [76]. Besides, this induction can be suppressed by neutralizing IL-9 antibody treatment [76].

\subsection{Cystic fibrosis transmembrane conductance regulator}

CFTR regulation of $\mathrm{Na}^{+}$channels balances $\mathrm{Na}^{+}$absorption and $\mathrm{Cl}^{-}$secretion to enable normal airway conditions [77]. CFTR is identified as a cAMP-dependent negative regulator of $\mathrm{Na}^{+}$channels and regulates $\mathrm{Na}^{+}$permeability of epithelial $\mathrm{Na}^{+}$channels [77]. Features of CFTR-related disorder are more commonly seen in severe asthma than non-severe asthma [78]. In one study, CFTR mutations were identified in $14 \%$ of one severe asthma cohort [78].

\section{Asthma and Sodium Channels}

\subsection{Voltage-gated $\mathrm{Na}^{+}$channels}

Like other voltage-gated ion channels, voltage-gated $\mathrm{Na}^{+}$ $(\mathrm{Nav})$ channels are composed of six transmembrane $\alpha$ helices (S1-S6) in each of the four homologous domains [79]. S1-S4 are voltage-sensing domains, and the loop between S5 and S6 forms the pore domain. They are mainly responsible for the rising phase of action potentials in the membranes of neurons and most electrically excitable cells [79].

$\mathrm{Na}_{\mathrm{V}}$ channels may contribute to airway contraction. Among $\mathrm{Na}_{\mathrm{V}} \mathrm{s}, \mathrm{Na}_{\mathrm{V}} 1.7$ may be a major contributor to action potential conduction because it is the most sensitive to and can be strongly inhibited by tetrodotoxin (TTX), which can block action potential conduction in C-fibers effectively [80]. This prevention of action potential conduction in the jugular C-fibers in the trachea inhibits sensory communication between the airways and brainstem, which may contribute to cough [80]. On the contrary, blocking of Nav1.8 inhibits TTX-resistant current [80].

Another putative contribution of $\mathrm{Na}_{\mathrm{V}}$ channels to asthma is mucus overproduction. The binding of $\mathrm{Na}_{\mathrm{V}}$ neurotoxins, such as polyether brevetoxins (PbTxs), to $\mathrm{Na}_{\mathrm{V}}$ channels, causes them to open at normal resting potentials with an increase in rate and may lead to 
decreased MCC and thus mucus overproduction [81]. In sheep models, after applying $\mathrm{Na}^{+}$channel blocker amiloride, a drug used in the treatment of $\mathrm{CF}$, the magnitude and the time-course of the increase in tracheal mucus velocity (TMV), a marker for MCC, is comparable with that achieved with $\beta$-naphthoyl-PbTx-3 and brevenal, which inhibit PbTx action [81]. Therefore, this study supports the hypothesis of the rationale behind the use of $\mathrm{Na}^{+}$channel blockers in treating CF: $\beta$-naphthoyl-PbTx-3 and brevenal stimulate TMV by blocking $\mathrm{ENaC}$ channels [81].

\subsection{Epithelial $\mathrm{Na}^{+}$channels}

The epithelial $\mathrm{Na}^{+}$channel $(\mathrm{ENaC})$ consists of three subunits $(\alpha, \beta$, and $\gamma)$ and is responsible for $\mathrm{Na}^{+}$absorption in epithelial cells [82]. The carboxyl terminals of the subunits are the least conserved segments [82]. All three subunits contain proline-rich segments in the carboxylterminal, which may determine the localization of $\alpha$ $\mathrm{rENaC}$ and binding of $\alpha$-spectrin to $\alpha$-rENaC [82]. Airway $\mathrm{ENaC}$ transport of $\mathrm{Na}^{+}$is not involved in overall salt balance unlike that of the kidney, colon, and sweat, and salivary ducts, but in maintaining the hydration level of the fluid layer lining the inner surface of the epithelium [82].

Like $\mathrm{Na}_{\mathrm{v}}$ channels, ENaCs may also contribute to mucus overproduction in the airways. So far, there are two families of ENaC identified in both alveolar type 1 (AT1) cells and type 2 (AT2) cells in the lung: highly selective cation (HSC) channels that transport $\mathrm{Na}^{+}$unidirectionally with low conductance of $\sim 6 \mathrm{pS}$ and amiloride-sensitive $\mathrm{Na}^{+}$channels that are nonselective cation (NSC) channels that have $\mathrm{Na}^{+}-\mathrm{K}^{+}$permeability of $\sim 1.4$ and larger conductance ranging between 19 and $30 \mathrm{pS}$ [83]. AT1 cells make up most of the lung surface area and may help maintain normal lung fluid balance, while AT2 cells take up less than $5 \%$ of lung surface and are important in net ion transport [84]. $\mathrm{Na}^{+}$transport in AT2 cells but not AT1 cells can be inhibited by nitric oxide, which is commonly used to treat respiratory diseases [84].

\section{Conclusion}

Asthma is chronic inflammatory disease of the airways that makes breathing difficult. The regulation of ion concentrations by ion channels either alone or in cooperation in both neuron and non-neuron cells are associated with the initiation and development of asthma. Activation of ion channels on epithelial cells and ASM cells mainly lead to $\mathrm{Ca}^{2+}$ influx and changes in membrane potential and thus airway remodeling; activation of ion channels on immune cells mainly causes the release of inflammatory mediators and thus airway inflammation; activation of ion channels, specifically TRP channels, on neurons mainly induce reflex responses like cough as well as airway remodeling. Although ion channels are already identified as key contributors in asthma and have been studied for decades, the involvement of recently discovered ion channels in asthma pathophysiology is not fully understood. Their contributions to asthma may be further studied, and they may be targeted for developing novel and effective pharmacological treatments for asthma.

\section{References}

1. Global Initiative for Asthma. Global Strategy for Asthma Management and Prevention, (2020).

2. T. Vos et al., Lancet, 390, 10100, pp. 1211-1259, (2017).

3. . Initiative, Rev. Française d'Allergologie d'Immunologie Clin., 36, 6, pp. 685-704, (1996).

4. M. Manise, G. Holtappels, K. Van Crombruggen, F. Schleich, C. Bachert, and R. Louis, PLoS One, 8, 3, (2013).

5. J. R. Murdoch and C. M. Lloyd, Mutat. Res. Fundam. Mol. Mech. Mutagen., 690, 1-2, pp. 24-39, (2010).

6. Y. D. Xu et al., Respir. Res., 11, pp. 1-11, (2010).

7. K. Raemdonck et al., Thorax, 67, pp. 19-25, (2012).

8. M. A. Twiss, E. Harman, S. Chesrown, and L. Hendeles, Br. J. Clin. Pharmacol., 53, 3, pp. 243-249, (2002).

9. W. A. Catterall, Cold Spring Harb. Perspect. Biol., 8, pp. 1-24, (2011).

10. J. Chen and M. J. Sanderson, J. Physiol., 10, pp. 3203-3218, (2017).

11. H. M. Rosenfeldt, Y. Amrani, K. R. Watterson, K. S. Murthy, R. A. Panettieri, and S. Spiegel, FASEB J., 17, 13, pp. 1789-1799, (2003).

12. S. C. Brennan et al., PLoS One, 8, 11, pp. 1-7, (2013).

13. K. E. Gabehart et al., Respir. Res., pp. 1-11, (2013).

14. C. H. Zhang, L. M. Lifshitz, K. F. Uy, M. Ikebe, K. E. Fogarty, and R. ZhuGe, PLoS Biol., 11, 3, (2013).

15. P. O. Girodet et al., Am. J. Respir. Crit. Care Med., 191, 8, pp. 876-883, (2015).

16. M. D. Cabral et al., Am. J. Respir. Crit. Care Med., 181, 12, pp. 1310-1317, (2010).

17. N. A. Barrett and K. F. Austen, Immunity, 31, 3, pp. 425-437, (2012).

18. H. Wang et al., Immunity, 44, 4, pp. 782-794, (2016).

19. M. Prakriya and R. S. Lewis, Physiol. Rev., 95, 4, pp. 1383-1436, (2015).

20. B. Y. R. K. Murray and M. I. Kotlikoff, pp. 123-144, (1991).

21. J. Sneyd et al., pp. 1-6, (2016).

22. K. Thurley et al., Sci. Signal., 7, 331, p. ra59, (2014).

23. K. Ohga, R. Takezawa, T. Yoshino, T. Yamada, Y. Shimizu, and J. Ishikawa, Pulm. Pharmacol. Ther., 21, 2, pp. 360-369, (2008).

24. J. Zou, Y. Gao, S. Geng, and J. Yang, Am. Physiol. Soc., pp. 1256-1263, (2011).

25. T. Trian et al., J. Exp. Med., 204, 13, pp. 3173-3181, (2007). 
26. M. D. Glitsch, D. Bakowski, and A. B. Parekh, EMBO J., 21, 24, pp. 6744-6754, (2002).

27. E. Rapizzi et al., J. Cell Biol., 159, 4, pp. 613-624, (2002).

28. G. Csordás et al., J. Cell Biol., 174, 7, pp. 915-921, (2006).

29. Q. Kuang, Cell. Mol. Life Sci., 72, pp. 3677-3693, (2015).

30. L. I. Brueggemann et al., Am. J. Physiol. - Lung Cell. Mol. Physiol., 302, 1, pp. 120-132, (2012).

31. L. I. Brueggemann et al., Am. J. Physiol. - Lung Cell. Mol. Physiol., 306, 6, pp. 476-486, (2014).

32. P. M. N. Menezes et al., J. Ethnopharmacol., 220, August 2017, pp. 16-25, (2018).

33. C. Dimitropoulou, R. E. White, D. R. Ownby, and J. D. Catravas, 32, pp. 239-247, (2005).

34. Z. Yu, Y. Wang, L. Qin, and H. Chen, Front. Pharmacol., 8, pp. 1-13, (2017).

35. D. Manzanares et al., Am. J. Physiol. - Lung Cell. Mol. Physiol., 306, pp. L453-L462, (2014).

36. M. C. Shepherd et al., 37, pp. 525-531, (2007).

37. E. Sa, A. Escalada, A. Celada, C. Solsona, and A. Felipe, Biochem. Biophys. Res. Commun., 352, pp. 913-918, (2007).

38. S. Koshy et al., J. Biol. Chem., 289, 18, pp. 1262312632, (2014).

39. S. Ghanshani et al., J. Biol. Chem., 275, 47, pp. 37137-37149, (2000).

40. S. Ø. E. O. Lesen, Physiology, 96, pp. 10917-10921, (1999).

41. E. Shumilina et al., J. Immunol., 180, 12, p. $8040=8047,(2008)$.

42. C. Miller, Genome Biol., 1, 4, pp. 1-5, (2000).

43. R. T. Ic, L. E. Chikashi, J. Ishikawa, and M. Asano, pp. 203-209, (1997).

44. W. Zhao, J. Zhang, Y. Lu, and R. Wang, EMBO J., 20, 21, pp. 6008-6016, (2001).

45. Y. Chen et al., Cytokine, 45, 2, pp. 117-123, (2009).

46. R. Fitzgerald et al., Biochem. Biophys. Res. Commun., 446, pp. 393-398, (2014).

47. C. Chen, R. Wang, S. Zhou, J. Zhao, and Y. Xu, Iran. J. Allergy, Asthma Immunol., 13, 6, pp. 420-427, (2014).

48. A. Di et al., Immunity, 49, pp. 56-65, (2018).

49. M. Gees, G. Owsianik, B. Nilius, and T. Voets, Compr. Physiol., 2, pp. 563-608, (2012).

50. M. Kollarik, F. Ru, and B. J. Undem, Pulm. Pharmacol. Ther., 20, 4, pp. 402-411, (2007).

51. S. Y. Leung et al., Cough, 3, 10, (2007).

52. L. Long et al., Respir. Res., 20, pp. 1-9, (2019).

53. J. Song et al., Sci. Rep., 7, 1, pp. 1-12, (2017).

54. G. Zhang, R. Lin, M. Wiggers, D. M. Snow, and L. Lee, J. Physiol., 23, pp. 5771-5786, (2008).
55. R. Rehman, Y. A. Bhat, L. Panda, and U. Mabalirajan, Int. Immunopharmacol., 15, 3, pp. 597-605, (2013).

56. S. Palaniyandi et al., Lab. Investig., 100, 2, pp. 265273, (2020).

57. J. Kim et al., Allergy Asthma Immunol. Res., 12, 4, pp. 684-700, (2020).

58. A. S. Sabnis, C. A. Reilly, J. M. Veranth, and G. S. Yost, Am. J. Physiol., 295, 1, pp. 194-200, (2008).

59. S. Ito et al., Pulm. Pharmacol. Ther., 21, pp. 812-817, (2008).

60. R. Vennekens et al., Nat. Immunol., 8, 3, pp. 312 320, (2007).

61. A. Sumoza-Toledo, A. Fleig, and R. Penner, J. Inflamm. (United Kingdom), 10, 1, pp. 1-8, (2013).

62. C. Nassenstein et al., J. Physiol., 6, pp. 1595-1604, (2008).

63. C. H. Du et al., Asian Pacific Soc. Respirol., 24, April, pp. 238-245, (2019).

64. L. Nesuashvili, S. H. Hadley, P. K. Bahia, and T. E. Taylor-clark, Mol. Pharmacol., 83, pp. 1007-1019, (2013).

65. M. J. Carr and B. J. Undem, Blackwell Sci., 8, pp. 291-301, (2003).

66. L. Zhang, X. An, Q. Wang, and M. He, J. Allergy Clin. Immunol., 141, 3, pp. 1074-1084, (2018).

67. V. Spahn, C. Stein, C. Zöllner, U. Berlin, O. Intensivmedizin, and V. S. Germany, Mol. Pharmacol., 85, February, pp. 335-344, (2014).

68. X. Zhang et al., J. Cell. Biochem., 119, 7, pp. 6033 6044, (2018).

69. H. Kalwa, H. Fehrenbach, T. Gudermann, A. Dietrich, and B. R. Rost, Clin. Exp. Allergy, 38, pp. 15481558, (2008).

70. T. J. Jentsch, V. Stein, F. Weinreich, and A. A. Zdebik, Physiol. Rev., 82, 2, pp. 503-568, (2002).

71. M. Toda, M. K. Tulic, R. C. Levitt, and Q. Hamid, J. Allergy Clin. Immunol., 109, 2, pp. 246-250, (2002).

72. Y. G. Alevy et al., J. Clin. Invest., 122, 12, pp. 45554568, (2012).

73. M. P. McLane et al., Am. J. Respir. Cell Mol. Biol., 19, 5, pp. 713-720, (1998).

74. M. Sala-rabanal, Z. Yurtsever, C. G. Nichols, and T. J. Brett, Elife, 4:e05875, pp. 1-14, (2015).

75. A. Lazrak et al., Am. J. Physiol. - Lung Cell. Mol. Physiol., 308, pp. L891-L903, (2015).

76. Y. Zhou et al., Am. J. Respir. Cell Mol. Biol., 25, 4, pp. 486-491, (2001).

77. M. J. Stutts et al., Science (80-. )., 269, 17, pp. 847850, (1995)

78. G. Riolo et al., Can. J. Respir. Crit. Care, Sleep Med., 3, pp. 76-83, (2018).

79. W. A. Catterall, Neuron, 26, pp. 13-25, (2000).

80. H. Sun, M. Kollarik, and B. J. Undem, Pulm. Pharmacol. Ther., (2017). 
81. W. M. Abraham et al., Am. J. Aspiratory Crit. Care Med., 171, pp. 26-34, (2005).

82. H. Garty and L. G. Palmer, Physiol. Rev., 77, 2, pp. 359-396, (1997).

83. C. A. Downs and M. N. Helms, Am. J. Physiol. Lung Cell. Mol. Physiol., 305, 20, pp. L595-L603, (2013).

84. M. N. Helms, L. Jain, J. L. Self, and D. C. Eaton, J. Biol. Chem., 283, 33, pp. 22875-22883, (2008). 